\title{
AISI 304 Steel Brazing Using A Flexible Brazing Foil Fabricated by Tape Casting Method
}

\author{
Ashutosh Sharma ${ }^{1}$, Soon-Jae Lee ${ }^{1}$, Joo-Hee $\mathrm{Oh}^{2}$, and Jae Pil Jung ${ }^{1 *}$ \\ ${ }^{1}$ Dept. of Materials Science and Engineering, University of Seoul, Seoul 02504, Republic of Korea \\ ${ }^{2}$ Korea Chemtech Co., Suwon 16681, Republic of Korea
}

\begin{abstract}
The authors report the fabrication of a flexible nickel brazing foil using powdered nickel alloy filler (BNi-2) mixed with an organic binder. The organic binder was composed of a polyacrylic acid polymer, glycol, carbon tetrachloride, and water as a dispersion medium for the powder. The brazing paste so formed was then tape-cast on a polymer foil with different polymer to paste (dispersant) ratios, of $\approx 9: 1,8: 2$ and 7:3 by weight, and was dried in a low-temperature oven. The filler pyrolysis temperature, paste spreading, permeability, and wettability were examined. The thermal analysis results showed that the filler paste decomposition temperature was in the range of $463-498{ }^{\circ} \mathrm{C}$, while the tape-cast brazing foil had a pyrolysis temperature of $\approx 334.36{ }^{\circ} \mathrm{C}$. The resulting flexible self-adhesive foil was used to braze steel foils. The AISI 304 steel joint microstructure and joint tensile shear tests were also performed. It was found that the brazing foil produced $\approx 1 \mathrm{wt} \%$ of residue after melting. The microstructural analysis showed a uniform distribution of a Cr-rich in Ni-rich matrix at a polymer to dispersant ratio of 8:2. It is suggested that the wettability of the brazing foil on AISI 304 steel will be maximum, and a higher joint strength can be obtained when the polymer to dispersant ratio is kept at 8:2.
\end{abstract}

(Received May 29. 2017; Accepted September 14, 2017)

Keywords: joining, brazing, stainless steel, adhesives, thermal analysis, flexible.

\section{INTRODUCTION}

Nickel-based brazing fillers (BNi) are used to join complex stainless steel shapes in multiple applications where extreme thermal resistance and high corrosion protection are required [1-2]. BNi fillers are used in a variety of industrial applications such as jet engines, turbine blades, chemical plants, nuclear reactors, and so on $[3,4]$. Various grades of $\mathrm{BNi}$ are available in the literature, where brazing with Ni-Cr-based filler materials (BNi-2 grade) is most popular [1-5]. These kinds of fillers are generally used in the form of powder, rod, or paste [5]. Joining stainless steel components with $\mathrm{BNi}-2$ fillers in a vacuum furnace has been one of the most important developments in industry in many decades [5].

In the current scenario, most of the brazing is carried out in vacuum, for example, on the order of $1 \times 10^{-4}$ Torr. In the vacuum process, the organic content of the brazing fillers may be adsorbed on the furnace walls, requiring further

*Corresponding Author: Jae Pil Jung

[Tel: +82-2-6490-2408, E-mail: jpjung@uos.ac.kr]

Copyright (c) The Korean Institute of Metals and Materials maintenance cost and waste of time [6,7]. In addition, organic residues in the melt will also restrict the fluid flow and hence deteriorate the wetting and brazeability [8]. Moreover, an inadequate brazing atmosphere may result in defective cracked joints and can cause insufficient strength and rigidity of the brazed parts. These problems become worse when brazing pastes are used. The decomposition of the flux during melting causes additional volatile residues $[5,9]$.

Amorphous brazing foils which contain no organic binders are also available in the literature but they are highly fragile and mostly used for flat tubes and cooler pipes [10,11]. For complex geometries and various complex joining situations where powder and pastes cannot be applied, a flexible brazing foil is needed.

There are various methods of fabricating micro-joining fillers (brazing pastes, solder films, etc.) which include mechanical mixing, alloying, melting and casting, rapid solidification methods, electroplating, etc. [5,12-14,13-32]. Traditional amorphous BNi brazing tapes made by gas atomization or melt spinning have uniform composition and minimum segregation. However, they require extremely high 
Table 1. The composition of the BrazeTec D1002.2 (BT) and $\mathrm{Ni}-\mathrm{Cr}(\mathrm{BNi}-2)$ powder.

\begin{tabular}{ccccccccc}
\hline Sample & Codes & $\begin{array}{c}\mathrm{Ni} \\
(\mathrm{wt} \%)\end{array}$ & $\begin{array}{c}\mathrm{Cr} \\
(\mathrm{wt} \%)\end{array}$ & $\begin{array}{c}\mathrm{Fe} \\
(\mathrm{wt} \%)\end{array}$ & $\begin{array}{c}\mathrm{Si} \\
(\mathrm{wt} \%)\end{array}$ & $\begin{array}{c}\mathrm{B} \\
(\mathrm{wt} \%)\end{array}$ & $\begin{array}{c}\mathrm{P} \\
(\mathrm{wt} \%)\end{array}$ & $\begin{array}{c}\mathrm{C} \\
(\mathrm{wt} \%)\end{array}$ \\
\hline $\begin{array}{c}\text { BrazeTec } \\
\text { D1002.2 }\end{array}$ & BT & 82 & 7 & 3 & 4.5 & 3.1 & 0.02 & 0.06 \\
\hline $\begin{array}{c}\text { BNi-2 } \\
\text { Powder }\end{array}$ & BNi-2 & $86-91$ & 7 & 3 & $\approx 4$ & $\approx 3$ & 0.02 & 0.06 \\
\hline
\end{tabular}

cooling rates (e.g. $10^{6} \mathrm{~K} \mathrm{~s}^{-1}$ ) to achieve the glassy phase $[5,20,33,34]$.

Therefore, in this study, a Ni brazing paste (BNi-2 grade) was tape cast on a polyurethane substrate to obtain a well-designed flexible nickel brazing foil. The paste characteristics and mechanical properties of the joint after applying the developed nickel foil were studied and compared with the properties of a commercial nickel-based brazing filler (BNi-2: Braz-Tech D1002.2) chosen as a reference.

\section{EXPERIMENTAL DETAILS}

\subsection{Binder materials}

The basic solution of organic binder was composed of a polyacrylic polymer and additives. The solvent used was a $\mathrm{CCl}_{4}$ solution. The thixotropic agent used was a glycerol derivative. The dispersing agent was a mixture of stearic acid and oleic acid. The pyrolysis temperature of the binder was determined after exposing it in vacuum at $500{ }^{\circ} \mathrm{C}$. The BNi-2 powders were supplied by Chem Tech, Korea. The reference powder was supplied by Braze-Tech D1002.2 (USA). The particle size of the filler powders was in the range of 1-5 $\mu \mathrm{m}$.

\subsection{Paste fabrication}

To prepare the brazing paste, the polymer binder and other additives with various contents were first dissolved in the $\mathrm{CCl}_{4}$ solvent and then mixed with BNi-2 powders, and stirred for 24 hours for proper homogenization. The sample designations and powder compositions (BNi-2, BT) are given in Table 1 and 2. The results of our experiment were compared with a reference brazing paste made by mixing a commercial BNi-2 (powder as a reference), labeled BT; Braze-Tech D1002.2 (USA) in Table 2, was also used for
Table 2. Composition of the brazing paste materials used in this study

\begin{tabular}{ccccc}
\hline Sample & Codes & $\begin{array}{c}\text { Powder } \\
(\text { BNi-2) } \\
(\text { wt } \%)\end{array}$ & $\begin{array}{c}\text { Thixotropic } \\
\text { agent }(w t \%)\end{array}$ & $\begin{array}{c}\text { Additives } \\
(\text { wt } \%)\end{array}$ \\
\hline BrazeTec D1002.2 & BT & 82 & $\approx 1$ & $\approx 1$ \\
\hline Chem-Tech NP 9-1 & CT1 & 91 & 1 & 1 \\
\hline Chem-Tech NP 12-1 & CT2 & 88 & 2 & 1 \\
\hline Chem-Tech NP 14-1 & CT3 & 86 & 3 & 1 \\
\hline Chem-Tech NP 14-2 & CT4 & 86 & 3 & 2 \\
\hline Chem-Tech NP 14-3 & CT5 & 86 & 3 & 3 \\
\hline
\end{tabular}

comparison.

\subsection{Brazing foil fabrication}

The polymer foil was chosen from a reactive hot melt (R-HM) thermo-softening polyurethane-based resin. The polyurethane foil was manufactured using spray coating and compression methods. Ni-brazing foil (thickness $\approx 0.2 \mathrm{~mm}$ ) was developed after casting brazing paste on the polymer foil followed by drying. Three types of foils were prepared with different polymer to dispersant ratios, varying from 9:1, 8:2, and 7:3.

\subsection{Differential thermal analysis (DTA)-thermogravimetric analysis (TGA)}

Since the Ni brazing foil was prepared using nickel paste containing organic binder, it was essential to evaporate the polymer before vacuum baking. To achieve this, the pyrolysis temperature of the brazing foil was measured using DTA-TGA analysis. For the polymer foil, the DTA-TGA measurement was carried out from 25 to $600{ }^{\circ} \mathrm{C}$ at a heating rate of $10{ }^{\circ} \mathrm{C} / \mathrm{min}$. For the $\mathrm{Ni}$ brazing foil, the measurements were done in the range of $25 \sim 1100 / 1200{ }^{\circ} \mathrm{C}$ at $2{ }^{\circ} \mathrm{C} / \mathrm{min}$. Nitrogen atmosphere at a flow rate of $200 \mathrm{~mL} / \mathrm{s}$ was utilized during the DTA-TGA scan. The weight of paste residue after melting was calculated after ultrasonic cleaning of the brazed specimen with a balance of least count $0.001 \mathrm{~g}$.

\subsection{Wettability test}

Stainless steel grade AISI 304 in dimensions of $20 \mathrm{~mm} \times 20$ $\mathrm{mm} \times 1 \mathrm{~mm}$ was used as substrates and the test was performed according to the standard [35]. The surface of the substrate (AISI 304 steel) was polished using \#2400 sandpaper and 


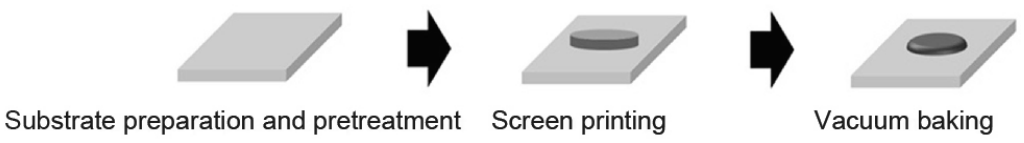

Fig. 1. Wettability schematic diagram.

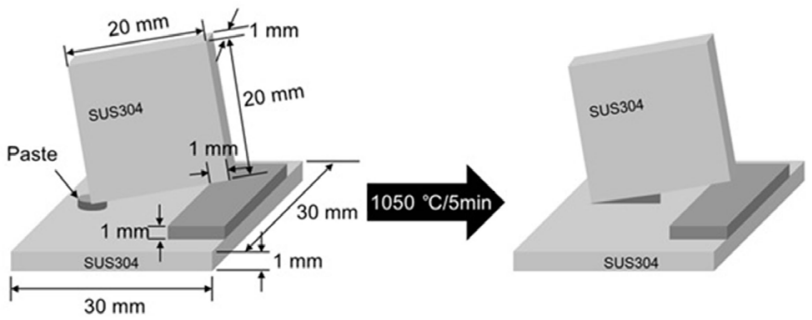

Fig. 2. Capillary permeability test.

pickled in $10 \% \mathrm{HCl}$ solution for 30 seconds followed by water rinsing. The paste was printed on substrates up to a thickness of $0.8 \mathrm{~mm}$ and a diameter of $5.5 \mathrm{~mm}$. After printing, the heat treatment was performed at various temperatures from 1000 , $1020,1050{ }^{\circ} \mathrm{C}$ at $5^{\circ} \mathrm{C} / \mathrm{min}$ for 5 minutes under $2.0 \times 10^{-5}$ Torr vacuum. The wetting angle of the paste was measured using an image analyzer (i-solution). A schematic of the wettability testing is given in Fig. 1.

\subsection{Capillary permeability analysis}

The capillary permeability test of the paste was performed by determining the length and height of the paste penetration according to the standard [36]. The pre-polished AISI 304 steel foils were used as substrates for the capillary permeability test. The test was performed on an AISI 304 plate at $1050{ }^{\circ} \mathrm{C}$ for 5 minutes under $2.0 \times 10^{-5}$ Torr vacuum, as shown in Fig. 2.

\subsection{Stainless steel brazing}

The AISI 304 steel foils were brazed with developed flexible Ni foil. The brazing was carried out at $1050{ }^{\circ} \mathrm{C}$ for 5 minutes under $\sim 2.0 \times 10^{-5}$ Torr. The surface of the AISI 304 foil was polished using a \#2400 sandpaper and was exposed to $10 \% \mathrm{HCl}$ solution for 30 seconds followed by cleaning with distilled water. The weight of the paste was measured immediately after brazing to measure the residue of the paste followed by ultrasonic cleaning in ethanol for 5 minutes. The

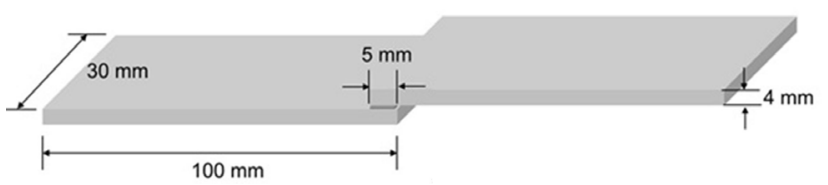

Fig. 3. Schematic diagram of the AISI 304 tensile specimen.

microstructure of the brazed joint was analyzed in a scanning electron microscope (SEM) and energy dispersive X-ray spectrometer (EDS).

\subsection{Tensile strength analysis}

The tensile testing on the brazed stainless steel (AISI 304) foils was performed using developed $\mathrm{Ni}$ foil [37]. The dimensions of the AISI 304 foils used for the tensile specimens were $100 \mathrm{~mm} \times 30 \mathrm{~mm} \times 4 \mathrm{~mm}$ as shown in Fig. 3. The surface to be bonded was ground with sandpaper (\#220) followed by ultrasonic cleaning in ethanol for 30 seconds. A tungsten wire (diameter: $0.1 \mathrm{~mm}$, length: $5 \sim 7$ $\mathrm{mm}$ ) was inserted into the joint to ensure a constant height. The brazing was carried out at a temperature of $1050{ }^{\circ} \mathrm{C}$ for 5 min under $\sim 2.0 \times 10^{-5}$ Torr. The heating rate of the brazing experiment was $5{ }^{\circ} \mathrm{C} / \mathrm{min}$. Three sets of tensile strength specimens of the AISI 304 substrates were prepared, corresponding to each temperature.

\section{RESULTS AND DISCUSSION}

\subsection{DTA-TGA Analysis}

Fig. 4 shows the DTA-TGA results of the Ni pastes and the developed $\mathrm{Ni}$ foil. It was observed that the samples showed a similar pyrolysis temperature irrespective of the additive concentration and polymer content. The pyrolysis temperature of the developed Ni pastes was around $467-496{ }^{\circ} \mathrm{C}$ (Fig. 4a). The standard sample (BT) showed a pyrolysis temperature ranging from $463-498{ }^{\circ} \mathrm{C}$ (Fig. $4 \mathrm{~b}$ ). The pyrolysis temperature of sample CT4 was lower than that of the standard BT sample 
(Fig. 4). The melting temperature of the CT4 sample also showed a drop by $1{ }^{\circ} \mathrm{C}$ as compared to the standard sample (BT). Other pastes with different binder compositions showed a similar behavior.

Fig. 4(c) shows the TG-DTA analysis of the brazing foil with polymer foil. The pyrolysis of the polymer began at $334.36{ }^{\circ} \mathrm{C}$, the decomposition temperature [38]. It can be seen that $47.24 \%$ of polymer was removed at around $100{ }^{\circ} \mathrm{C}$ and $58.96 \%$ of the polymer was removed at around $300{ }^{\circ} \mathrm{C}$. Similarly, 79.04\% was removed at around $400{ }^{\circ} \mathrm{C}$ and most of the polymer $99.63 \%$ was removed at around $470{ }^{\circ} \mathrm{C}$. TGA measurement results of the paste were found to be in a good agreement with that of other binder pastes. For example, in a brazing foil with a ratio of polymer to dispersant of 9:1
(CT4-9:1), most of the polymer was removed by heating beyond $467{ }^{\circ} \mathrm{C}$. The pyrolysis temperature was around $470{ }^{\circ} \mathrm{C}$, and more than $99 \%$ of the polymer had disappeared at $500{ }^{\circ} \mathrm{C}$.

The developed brazing foil was flexible, as shown in the inset of Fig. 4(c), and can be deformed freely without any breakage, irrespective of the polymer to dispersant ratio. It was observed that the brazing foil could not be easily torn by hand, and no filler metal was detached after touching. The thickness of each foil was measured with a Vernier caliper and was found to lie in the range of $0.3-0.5 \mathrm{~mm}$.

\subsection{Wettability analysis}

The wetting angle of the melt was measured after solidifying on stainless steel substrates (AISI 304). The fillers

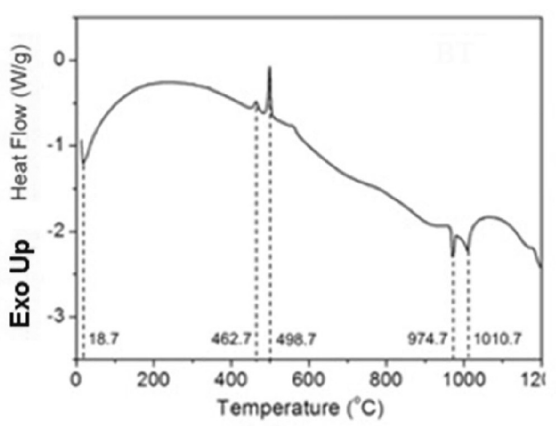

(b)

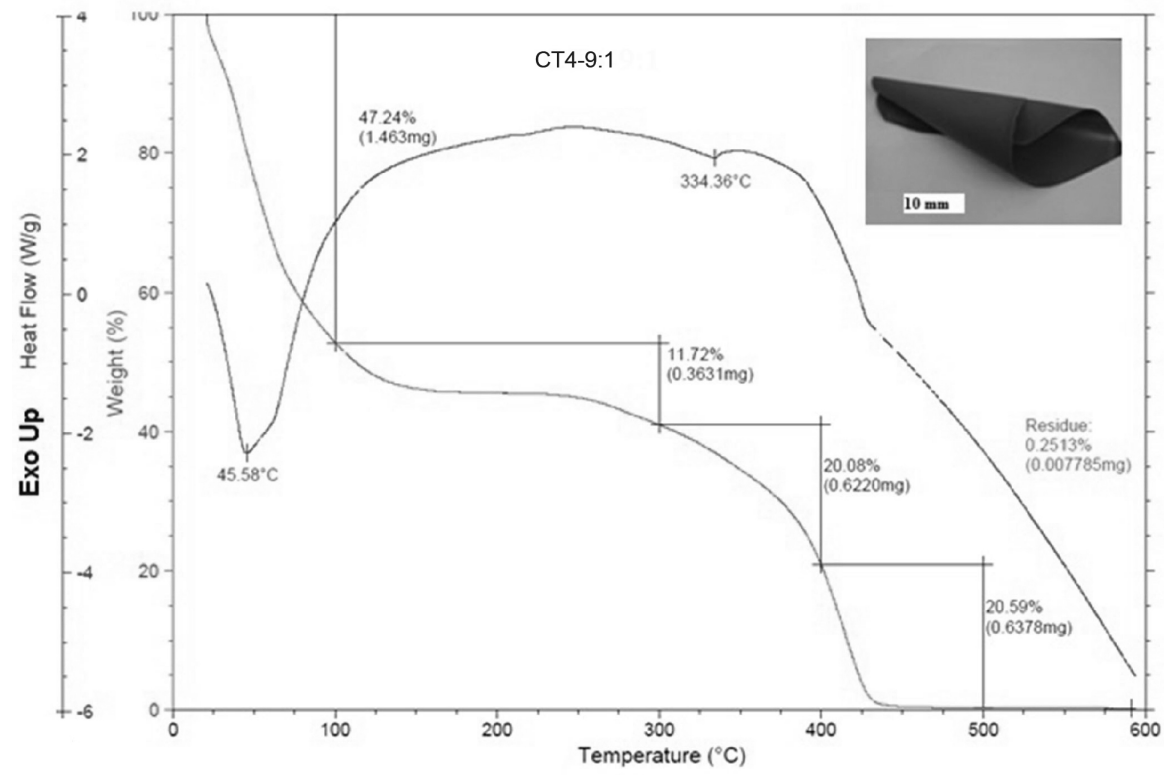

(c)

Fig. 4. DTA-TGA curve of BNi-2 type paste: (a) CT4, (b) BT, and (c) developed CT4 paste brazing foil with polymer to dispersant ratio of $9: 1$, and pyrolysis temperature of $334.36{ }^{\circ} \mathrm{C}$. The inset shows the real image of developed flexible brazing foil. 
Table 3. Spreading area of the spread images after the heat treatment at various temperatures.

\begin{tabular}{cccc}
\hline \multirow{2}{*}{ Samples } & \multicolumn{3}{c}{ Spreading area $\left(\mathrm{cm}^{2}\right)$} \\
\cline { 2 - 4 } & $1000{ }^{\circ} \mathrm{C}$ & $1020{ }^{\circ} \mathrm{C}$ & $1050{ }^{\circ} \mathrm{C}$ \\
\hline BT & 1.33 & 1.364 & 1.518 \\
\hline CT1 & 1.189 & 1.537 & 1.531 \\
\hline CT2 & 1.209 & 1.509 & 1.595 \\
\hline CT3 & 1.288 & 1.460 & 1.482 \\
\hline CT4 & 1.438 & 1.383 & 1.371 \\
\hline CT5 & 0.941 & 0.964 & 1.535 \\
\hline
\end{tabular}

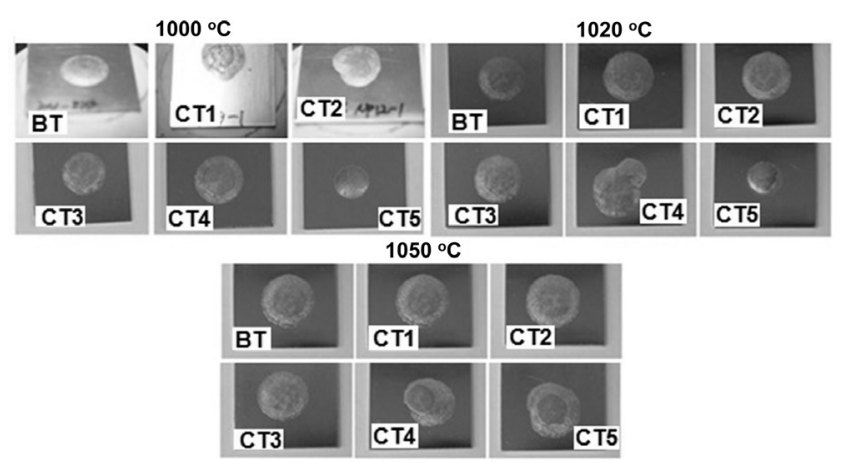

Fig. 5. Wettability images of various brazing pastes on AISI 304 at various temperatures.

were melted at temperatures of 1000,1020 , and $1050{ }^{\circ} \mathrm{C}$ for 5 minutes and the spreading area was calculated (Table 3). It was found that the spreading area of all the samples increased linearly with temperature, as shown in Fig. 5. It can be seen that the spreading area increases with the type of sample, e.g., $\mathrm{CT} 1, \mathrm{CT} 2, \mathrm{CT} 3$, and CT4, respectively. The spreading area also increased continuously from 1000 to $1020{ }^{\circ} \mathrm{C}$ but increased steadily at $1050{ }^{\circ} \mathrm{C}$. It was also observed that with an increase in temperature, the spreading area became very poor in CT5 and indicated de-wetting of nickel paste on AISI 304 foil (Fig. 5). Sample CT5 showed the lowest value for the measured spreading area as calculated (Table 3). This indicates poor wetting in the presence of a higher amount of polymeric additives, which may segregate after melting and restrict the melt fluidity [39-41]. To study the wetting behavior of brazing pastes more accurately, the wetting angle between the molten metal and substrate was calculated and plotted, as shown in Fig. 6.

It can be seen that the wetting angle decreases at higher temperature for all the samples. The standard sample (BT)

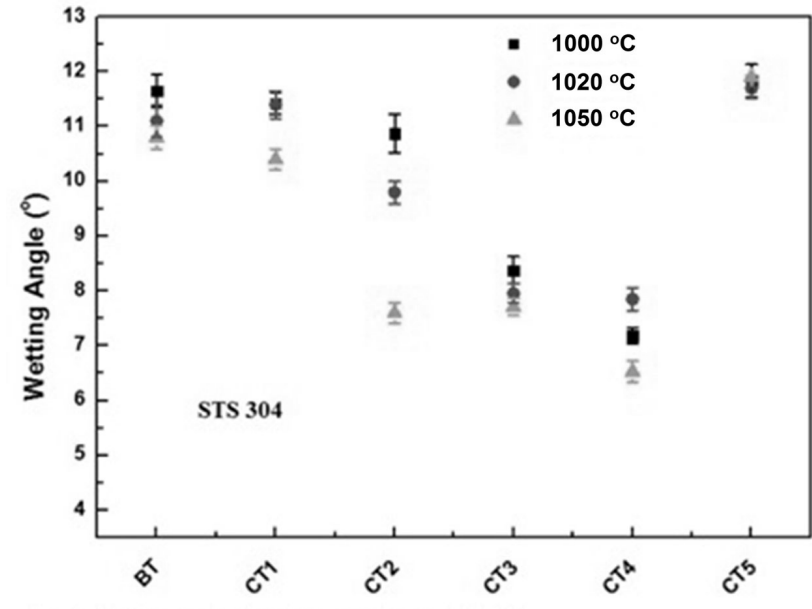

Fig. 6. Wetting angle of various samples on AISI 304

showed a wetting angle varying from $10.5^{\circ}$ to $11.5^{\circ}$ at different temperatures, and the wetting angle decreased with increasing temperature. This may be due to the increase in the fluidity of the paste with temperature.

Moreover, the rate of increase in the wetting angle increased slightly at $1050{ }^{\circ} \mathrm{C}$. For example, the wetting angle was lower for the other samples CT1, CT2, CT3 and CT4 compared to the standard BT sample. These samples contained a high amount of Ni compared to the BT sample. Moreover, the presence of the thixotropic agent and dispersants in the brazing pastes helps to maintain fluidity and create a wettable layer over the solder fillet.

As recently reported by Sharma et al., the polymeric layers over solder may provide an anti-oxidation (corrosion resistance) property which is also beneficial for the joint [14] The sample CT4 showed the least wetting angle $\left(\approx 6^{\circ}\right)$ with better wetting properties. However, the wetting angle of sample CT5 was higher and similar to the standard sample (BT). This indicates that the CT5 sample has poor wetting properties. This may be due to the fact that there was a higher amount of metal content and polymer additives in CT5, as compared to the other brazing pastes. As a consequence, the viscosity of the brazing paste increased and prevented the molten liquid from flowing further. This means, above a critical loading, an aggregation of polymer residues exists which leads to weakening of the structure. [39-41,42,43]. The 
Table 4. Characteristics of brazing sheet before and after pretreatment

\begin{tabular}{cccccc}
\hline Sample & $\begin{array}{c}\text { Wi } \\
(\mathrm{g})\end{array}$ & $\begin{array}{c}\text { Wf } \\
(\mathrm{g})\end{array}$ & $\begin{array}{c}\text { Residue } \\
(\mathrm{g})\end{array}$ & $\begin{array}{c}\text { SA } \\
\left(\mathrm{cm}^{2}\right)\end{array}$ & $\begin{array}{c}\text { Wetting } \\
\text { angle }(\mathrm{o})\end{array}$ \\
\hline CT4-9:1 & 6.971 & 6.968 & 0.003 & 0.671 & 15.828 \\
\hline CT4-8:2 & 6.983 & 6.982 & 0.001 & 1.010 & 8.221 \\
\hline CT4-7:3 & 6.972 & 6.970 & 0.002 & 0.871 & 11.486 \\
\hline
\end{tabular}

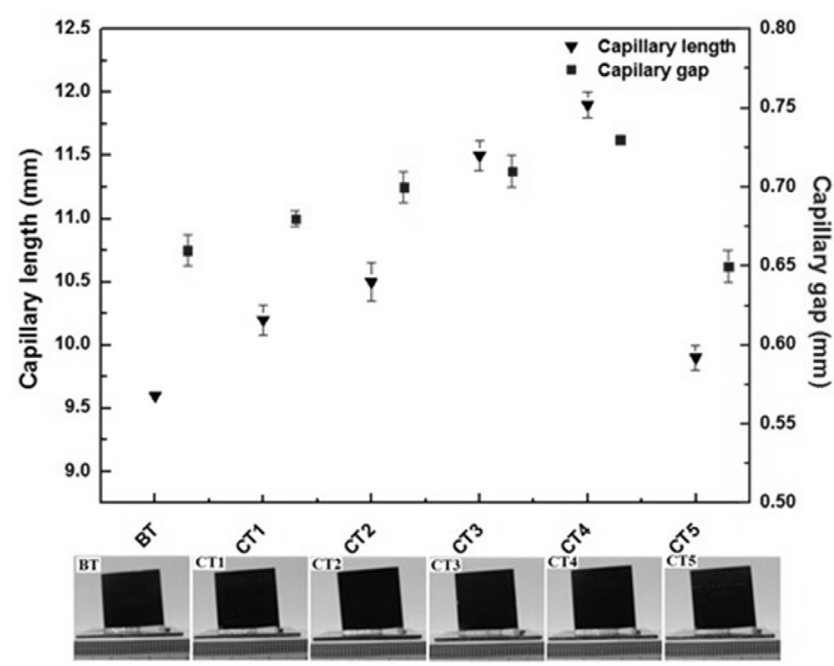

Fig. 7. Capillary permeability length and gap size of various samples $\left(1050{ }^{\circ} \mathrm{C}\right.$ and $\left.5 \mathrm{~min}\right)$.

unreacted organic additive in the CT5 paste outgassing from the melt and hence produces de-wetting on steel foils [39-43].

\subsection{Capillary permeability}

The capillary permeation length and gap images of all the nickel brazing pastes are shown in Fig. 7. When the temperature was kept at $1050{ }^{\circ} \mathrm{C}$ for 5 minutes, all the samples showed a penetration length between mosaics of 10.2 $\sim 12.0 \mathrm{~mm}$, while the standard sample BT had a penetration length of $\approx 9.6 \mathrm{~mm}$. The capillary penetration clearance was in the range of $0.66 \sim 0.74 \mathrm{~mm}$, which was equal to or higher than that of the standard BT sample. This shows that the developed Ni brazing paste can more easily penetrate to the substrate joints and can provide excellent bonding strength. The capillary penetration length and gap showed a decreasing trend in sample CT5, which was also consistent with those of the wetting results [39-42]. A higher binder content may produce significant residue after melting, and may cause poor flow and penetration length $[39,42]$.
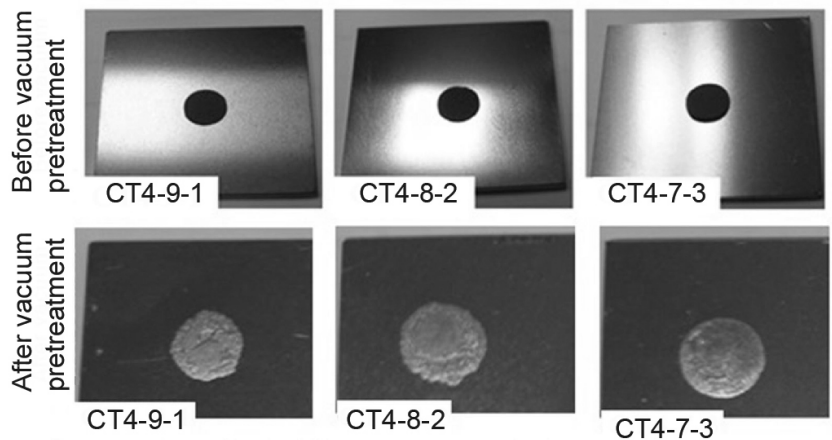

Fig. 8. Shape change of brazing foil before and after vacuum brazing pretreatment.

\subsection{Polymer foil residue}

Fig. 8 shows the pre- and post-heat treatment images of the samples after vacuum brazing. It was shown that the shape of the brazing pastes after melting changed after the vacuum heat treatment. The weight changes, residue, spreading area (SA) and the wetting angle were calculated, as shown in Table 4.

The brazing paste CT4 was selected as a dispersant for the polymer foil because it had the best wetting and capillary penetration properties among the other developed pastes. The polymer to dispersant (paste) ratio was varied from 9:1, 8:2, to 7:3. It was observed that the higher the amount of dispersant in the foil, the higher the spreading ratio and the wetting angle were. The weight change after melting of the brazing foil also dropped from 0.003 to $0.001 \mathrm{~g}$ due to the evaporation of the polymer. However, the sample with a $7: 3$ dispersant ratio showed an increased wetting angle. The overall residue increased slightly to $0.002 \mathrm{~g}$. Although there was a slight increase in the residue, the wettability degraded to a greater extent. This may be due to the increasing amount of dispersant in the brazing foil (i.e., CT4-7:3) which got burnt out, producing residue which obstructed the flow of the molten filler [13,39-43].

\subsection{Microstructure of the brazing part}

The cross-sections of the different joints brazed using the developed brazing foil were analyzed by SEM (Fig. 9). The brazed joint thickness of the specimens brazed with CT4-9:1 and CT4-8:2 were about 114 and $110 \mu \mathrm{m}$, respectively, but the joint thickness of the brazed specimens using CT4-7:3 
Table 5. Results of EDS analysis

\begin{tabular}{|c|c|c|c|c|c|c|}
\hline \multirow{3}{*}{ Elements } & \multicolumn{2}{|c|}{ CT4-9:1 } & \multirow{2}{*}{\multicolumn{2}{|c|}{$\begin{array}{c}\text { CT4-8:2 } \\
\text { Composition } \\
(\mathrm{wt} \%)\end{array}$}} & \multicolumn{2}{|c|}{ CT4-7:3 } \\
\hline & & & & & & \\
\hline & (1) & (2) & (1) & (2) & (1) & (2) \\
\hline B & 2.90 & - & 2.03 & - & 2.61 & - \\
\hline $\mathrm{C}$ & 12.41 & 11.24 & 12.76 & 11.65 & 12.51 & 10.82 \\
\hline $\mathrm{O}$ & - & 0.74 & - & 0.70 & - & - \\
\hline $\mathrm{Si}$ & - & 11.38 & - & 6.49 & - & 1.71 \\
\hline $\mathrm{Cr}$ & 58.02 & 0.91 & 60.09 & 3.30 & 63.85 & 4.29 \\
\hline $\mathrm{Fe}$ & 4.84 & 1.64 & 3.09 & 5.05 & 1.93 & 5.49 \\
\hline $\mathrm{Ni}$ & 21.83 & 74.09 & 22.03 & 72.81 & 19.1 & 77.69 \\
\hline Total & 100 & 100 & 100 & 100 & 100 & 100 \\
\hline
\end{tabular}

was about $65 \mu \mathrm{m}$.

The various phases present in the joint were analyzed by EDS. The composition of the various phases is given in Table 5. Regardless of the brazing foil type, a $\mathrm{Cr}$ rich composition was shown in (1) and a Ni-rich composition in (2). In addition, there was about $2 \mathrm{wt} \%$ of B in (1), but B was not detected in (2). In both (1) and (2), about $\approx 10-12 \mathrm{wt} \%$ of $\mathrm{C}$ were present. The presence of $\mathrm{C}$ was nearly same in all locations and may have come from the organics added during the paste fabrication.

An EDS analysis was performed across the brazed joint as shown in the respective spectrum 1-2. The matrix is Ni-rich with an island Cr-B rich phase, as shown in Fig. 9. It was observed that the brazing foil with a polymer to dispersant ratio of 9-1 (CT4-9:1) had a higher content of $\mathrm{Cr}$ rich phase, $\approx$ $58 \%$, dispersed in the Ni rich matrix. This indicated a uniform composition across the brazed joint. However, the density of the Cr-rich phase was higher in 8:2, and $\mathrm{Cr}$-rich phases $(\mathrm{Cr} \approx$ $60 \%$ ) were found to disperse more uniformly. The uniform distribution of the secondary phases has been shown to contribute to strengthening in the past [41,42]. The mechanical properties only improve if there is a proper dispersion of the second phase particles. In contrast, poor dispersion may also give poor results. For example, in specimen (CT4-7:3), the matrix region across the joint showed a concentration of Cr-rich phase $\approx 64 \%$ localized in the Ni-rich matrix. It is already known that a localized dispersion of second phase particles may degrade the microstructural properties [41-43].

\subsection{Tensile testing}

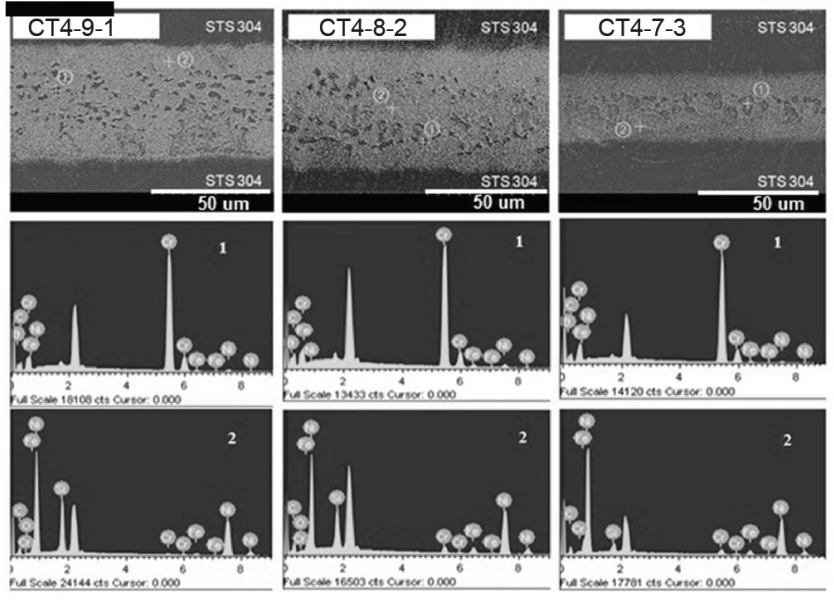

Fig. 9. Brazed joint microstructures using the developed nickel brazing foil with different polymer to dispersant ratios.

The tensile results of the specimens brazed at $1050{ }^{\circ} \mathrm{C}$ for 5 minutes in a lap joint configuration were obtained from the tensile testing specimen, as shown in Fig. 10. For tensile tests, the brazing temperature was fixed at $1050{ }^{\circ} \mathrm{C}$ near the liquidus point of the filler. This is in accordance with the American Welding Society guidelines, i.e., a brazing temperature $\approx 1050{ }^{\circ} \mathrm{C}$ [44]. It was noticed that the UTS and the strain followed a similar trend. The UTS and strain were best at the polymer to dispersant ratio of $8: 2$. This may be due to the higher population density of the Cr-rich phases in the Ni matrix, as observed from the SEM analysis. The mean values of the UTS and the strain are given in Table 6. It was observed that the tensile strength of the sample CT4-9-1 containing a polymer to dispersant ratio $\approx 9: 1$ was around 194 $\mathrm{MPa}$. The tensile strength increased when the polymer to dispersant ratio was increased further to $8: 2$. The strain value was also found to increase as a consequence, as shown in Table 6. It was also observed that when the polymer to dispersant ratio reached $7: 3$, the tensile strength dropped drastically to $169 \mathrm{MPa}$. The strain values also dropped significantly. This may be due to the fact that a higher concentration of dispersant will also increase the organic residues, and reduce the wetting, as was already observed from the wetting results [39-43,44-46].

This means that a ratio of $8: 2$ is sufficient to stabilize the BNi-2 powder in the paste, and thus a uniform brazing foil can be produced with a higher strength. From the SEM 


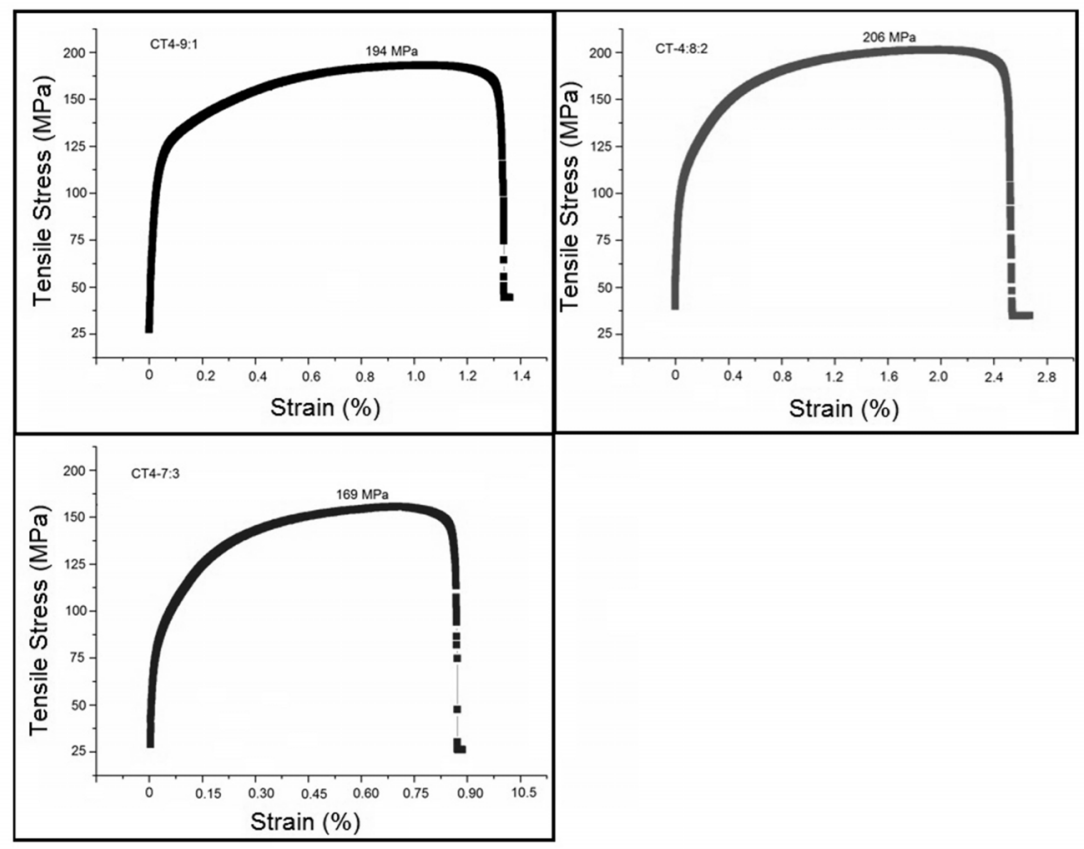

Fig. 10. The ultimate tensile strength and strain produced in the samples after tensile shear test of AISI 304 joint.

Table 6. Tensile characteristics.

\begin{tabular}{ccc}
\hline Samples & Tensile strength $(\mathrm{MPa})$ & Strain $(\%)$ \\
\hline CT4-9:1 & $194 \pm 5$ & 1.3 \\
\hline CT4-8:2 & $206 \pm 8$ & 2.5 \\
\hline CT4-7:3 & $169 \pm 4$ & 0.8 \\
\hline
\end{tabular}

results, it was also noticed that the interfacial zone was minimum, and the distribution of Cr-rich phases was not uniform in the case of sample CT4-7-3. A reduced interfacial zone indicated a poor interfacial reaction and brazeability, which may cause a quick failure [47-49].

\section{CONCLUSIONS}

1. A flexible nickel brazing foil was successfully prepared from $\mathrm{BNi}-2$ powder mixed with an organic binder consisting of a polyacrylic acid polymer, glycol, and carbon tetrachloride, by tape casting on a polyurethane substrate.

2. Differential thermal analysis results showed that the pyrolysis temperatures of the pastes were in the range of 463-498 ${ }^{\circ} \mathrm{C}$, while the tape cast brazing foil had a pyrolysis temperature near $\approx 334.36{ }^{\circ} \mathrm{C}$.

3. The wetting behavior of the developed $\mathrm{Ni}$ paste on the
AISI 304 showed that sample CT4 had the least wetting angle and capillary permeability. The wetting was reduced further in sample (CT5) with increasing organic additives contents, which may produce undesirable burnt out residues. The wetting also increased linearly with temperature, as well as with the organic binder content. The wettability behavior was improved when the brazing foil was prepared with an optimum value of polymer to dispersant ratio of $8: 2$.

3. The microstructural analysis showed a reduction in the interfacial zone when the polymer to dispersant ratio was increased to $7: 3$, as compared to when the ratios were $9: 1$ and $8: 2$. A uniform distribution of $\mathrm{Cr}$-rich in Ni-rich matrix phases was obtained at a polymer to dispersant ratio of 8:2.

4. It is reported that the tensile strength of the joint brazed using the developed fillers had higher strength with a polymer to dispersant ratio of $8: 2$. Therefore, this study suggested an optimum value of polymer to dispersant ratio of $8: 2$ for better brazeability and strength.

\section{ACKNOWLEDGEMENTS}

This work was supported by the Technological Innovation R\&D Program (No.: S2517123) funded by the Small and 
Medium Business Administration (SMBA, Korea).

\section{REFERENCES}

1. E. Lugscheider and K. D. Partz, Weld. J. 62, 160 (1983).

2. Y. Miyazawa, K. Ohta, and A. Nishiyama, IOP Conf. Series: Mater. Sci. Eng. 61, 012014 (2014).

3. G. Stratford, A. Battenbough, L. Lee, and M. Weinstein, Weld. J. 3, 54 (2011).

4. R. P. Schaefer, J. E. Flynn, and J. R. Doyle, Weld. J. 9, 394 (2017).

5. M. Schwartz, Brazing: For the Engineering Technologist, 1st ed. Springer Science \& Business Media, Netherlands (1994).

6. J. Kowalewski and J. Szczurek, Heat Treat. Prog. 6, 41 (2006).

7. T. Hartmann and D. Nützel, Proc. 4th Int. Brazing ans Soldering Conference, Orlando, Florida (2009).

8. D. M. Jacobson and G. Humpston, Principles of Brazing, ASM International, USA (2005).

9. T. Hartmann and D. Nützel, Proc. 9th Int. Conf. of Brazing, LÖT 2010, (DVS-Berichte 263), Aachen, Germany (2010).

10. T. Hartmann, and D. Nützel, In: 5th Int. Conf. on Brazing and Soldering Conference, Las Vegas (2012).

11. V.-A. Şerban and C. Codrean, Welding \& Material Testing, 22, 13 (2013).

12. A. Sharma, Y. J. Jang, and J. P. Jung, Surf. Eng. 31, 458 (2015).

13. A. Sharma, S. Bhattacharya, S. Das, and K. Das, Appl. Surf. Sci. 290, 373 (2014).

14. A. Sharma, K. Das, H. J. Fecht, and S. Das, Appl. Surf. Sci. 314, 516 (2014).

15. A. Sharma, D.-U. Lim, and J.-P. Jung, Mater. Sci. Technol. 32, 773 (2016).

16. A. Sharma, M.-H. Roh, D. H. Jung, and J. P. Jung, Metall. Mater. Trans. A 47, 510 (2016).

17. A. Sharma, Y. J. Jang, J. B. Kim, and J. P. Jung, J. Alloy. Compd. 704, 795 (2017).

18. A. Sharma, M. H. Roh, and J. P. Jung, J. Mater. Eng. Perform. 25, 3538 (2016).

19. A. Sharma, S. H. Kee, F. Jung, Y. Heo, and J. P. Jung, J. Mater. Eng. Perform. 25, 1722 (2016).

20. J. R. Davis, Nickel, Cobalt, and Their Alloys, ASM Specialty Handbook, ASM International, USA (2000).

21. J. S. C. Jang and H. P. Shih, Mater. Chem. Phys. 70, 217 (2001).

22. M. H. Roh, A. Sharma, J. H. Lee, and J. P. Jung, Metall. Mater. Trans. A 46, 2051 (2015).

23. D. H. Jung, A. Sharma, K. H. Kim, Y. C. Choo, and J. P. Jung, J. Mater. Eng. Perform. 24, 1107 (2015).
24. A. Sharma, S. Das, and K. Das, Surf. Coat. Technol. 261, 235 (2015).

25. A. Sharma, S. Bhattacharya, S. Das, and K. Das, Surf. Eng. 32, 378 (2016).

26. A. Sharma, D. H. Jung, M. H. Roh, and J. P. Jung, Electron. Mater. Lett. 12, 856 (2016).

27. A. Sharma, S. Das, and K. Das, Electrodeposition of Composite Materials (ed. Dr. A.M.A. Mohamed), InTech (2016).

28. A. Sharma, S. Das, and K. Das, Electroplation of Nanostructures (ed. Aliofkhazraei M), InTech (2015).

29. A. Sharma, S. Das, and K. Das, Microelectron. Eng. 170, 59 (2017).

30. S. Bhattacharya, A. Sharma, S. Das, and K. Das, Metall. Mater. Trans. A 47, 1292 (2016).

31. A. Sharma, Y. J. Jang, and J. P. Jung, J. Mater. Eng. Perform (In press).

32. A. Sharma, K. Das, and S. Das, J. Electron. Mater. 46, 5855 (2017).

33. W. Yu, W. Lu, and N. Li, Adv. Mater. Res. 583, 268 (2012).

34. Y. Miyazawa and T. Ariga, Mater. Trans. 33, 519 (1992).

35. Testing Methods for Soldering Fluxes, Japanese Industrial Standards, JIS Z-3197 (2012).

36. LWS T 8801 Standard, Japan Light Metal Welding \& Construction Association (1991).

37. Tension Testing of Metallic Materials, ASTM E-8-04, ASTM International, USA

38. C. L. Beylor and M. M. Hirschler, Thermal Decomposition of Polymers, SFPE Handbook of Fire Protection Engineering, 3rd ed., sect. 1, chap. 7, 1-110 (2001).

39. A. Sharma, D. E. Xu, J. Chow, M. Mayer, H.-R. Sohn, and J. P. Jung, Electron. Mater. Lett. 11, 1072 (2015).

40. H. Y. Lee, A. Sharma, S. H. Kee, Y. W. Lee, J. T. Moon, and J. P. Jung, Electron. Mater. Lett. 10, 997 (2014).

41. A. Sharma, H.-R. Sohn, and J. P. Jung, Metall. Mater. Trans. A 47A, 494 (2016).

42. A. A. Moosa, A. Ramazani S. A., F. A. Karim Kubba, and M. Raad, American J. Mater. Sci. 7, 1 (2017).

43. J. Zhu, Suying Wei, J. Ryu, M. Budhathoki, G. Liang, and Z. Guo, J. Mater. Chem. 20, 4937 (2010).

44. A. Rabinkin, Sci. Technol. Weld. Joining, 9, 181 (2004).

45. S.-Y. Fu, X.-Q. Feng, B. Lauke, and Y.-W. Mai, Composites: Part B 39, 933 (2008).

46. N. Domun, H. Hadavinia, T. Zhang, T. Sainsbury, G. H. Laghat, and S. Vahid, Nanoscale 7, 10294 (2016).

47. T. F. Song, X. Jiang, Z. Shao, D. Mo, D. Zhu, and M. Zhu, Metals 6, 263 (2016).

48. S.-J. Han, J. Seo, K.-H. Choe, and M.-H. Kim, Met. Mater. Int. 21, 270 (2015).

49. B. R. Jin and C. Y. Jeong, Korean J. Met. Mater. 54, 626 (2016). 